Volume 8. No. 4, April 2020

International Journal of Emerging Trends in Engineering Research

Available Online at http://www.warse.org/IJETER/static/pdf/file/ijeter02842020.pdf

https://doi.org/10.30534/ijeter/2020/02842020

\title{
Effect of Thermal and Thermomechanical Load on Strain in Functionally Graded Material Plate for Varying Aspect Ratio under Constant and Variable Thermal Environment
}

\author{
Manish Bhandari \\ Mechanical Engg. Department, MBM Engg. College, JNV University, Jodhpur-342001
}

\begin{abstract}
Functionally graded material (FGM) are made of mixture of ceramic and metals. The ceramic constituent of the FGM material has lesser thermal conductivity and hence provides resistance to high temperature. The ductile metal constituent of FGM has high temperature gradient and hence provide resistance to thermal stresses and prevents the fracture. A lot of experimental, numerical and analytical techniques have been used in recent years to analyze the behavior of FGMs. The characteristics of FGM plate are studied when subjected to various types of thermal loading and thermo-mechanical loading. In this paper the thermal analysis of FGM plate under thermal environment is performed. The work includes studying the effect of various volume fraction exponents and temperature variation on the performance of FGM. The thermal analysis of FGM plate is conducted using finite element model developed and the ANSYS software is being used for computing the thermal response. The FGM plate is assumed to be made of Aluminum and Zirconia and the results are presented in terms of nondimensional parameters e.g. strain and shear strain.
\end{abstract}

Keywords: FEM, FGM, Shear strain, Strain, Thermomechanical.

\section{INTRODUCTION}

Functionally graded material (FGM) are made of mixture of ceramic and metals. The ceramic constituent of the FGM material has lesser thermal conductivity and hence provides resistance to high temperature. The ductile metal constituent of FGM has high temperature gradient and hence provide resistance to thermal stresses and prevents the fracture.A lot of experimental, numerical and analytical techniques have been used in recent years to analyze the behavior of FGMs. Butcher et. al. [1] measured spatial gradation of Young's modulus in functionally grade materials using optical interferometry. Zhen [2] obtained deformations due to the temperature varying only in the thickness direction analytically by asymptotic expansion method. Dai et. al. [3] used higher order shear and normal deformable plate theory (HOSNDPT) and the mesh-less local Petrov-Galerkin method (MLPG) to derive the shape functions. Yasser [4] used homogenization method and found that the square arrangements of the fibers reinforcements predict higher values of Young's modulus than hexagonal one. Kyung and Hwan [5]presentedanalysis of stress for plates made of FGcomposite using 3-D FEM. They modeled the plate using an equivalent single layer theory. The governing equations of motion were derived from Hamilton's principle. Momennia and Akbarzadeh [6] performed all simulations by developing finite element programs in order to evaluate all of the thermally independent effective properties for each ceramic volume fraction and the meshes are generated by the commercial finite element package ABAQUS. Vanam et. al. [7] developed finite element model based on FSDT plate theory and minimum potential energy principal. Nguyen et. al. [8] developed an efficient finite NS-DSG3 element for analysis of FGM plate which results in coupling of FEM and mesh-free method. Bhandari and Purohit [9] used finite element formulation and ANSYS to perform thermomechanical analysis of FGM plate. Sharma et.al. $[10,11]$ conducted a comparison and analysed buckling loads at critical thermal conditions of FGmaterial plate for various thermal profiles. The characteristics of FGM plate are studied when subjected to various types of thermal loading and thermo-mechanical loading. In this paper the thermal analysis of FGM plate under thermal environment is performed. The work includes studying the effect of various volume fraction exponents and temperature variation on the performance of FGM. The thermal analysis of FGM plate is conducted using finite element model developed and the ANSYS software is being used for computing the thermal response. The FGM plate is assumed to be made of Aluminum and Zirconia and the results are presented in terms of nondimensional parameters e.g. strain and shear strain.

\section{METHODOLOGY}

Finite Element Analysis (FEA) has become a vital tool for the design of structures or components formed by heterogeneous objects. Various packages comprise properties of user friendliness, wide variety of mechanical problems which includes static and dynamic structural analysis (both linear and non-linear), library of elements, graphical and animated presentations of results etc. The thermal analysis of FGM plate is conducted using finite element model developed and the ANSYS software is being used for computing the thermal response. The FGM plate is assumed to be made of Aluminum and Zirconia.

The thermal and thermomechanical analysis for the following conditions are performed:

a. Constant thermal environment: The FGM plate is subjected to a constant temperature. The ceramic surface is exposed to a temperature of $100^{\circ} \mathrm{C}$ and aspect ratio of the plate is varying. 
Manish Bhandari, International Journal of Emerging Trends in Engineering Research, 8(4), April 2020, 950 - 955

b. Constant thermal environment under mechanical load: In this part of analysis the FGM plate is subjected to constant temperature and constant mechanical load. The top surface (ceramice) of FGM plate isapplied with a temperature $100^{\circ} \mathrm{C}$. The value of the mechanical load i.e. uniformly distributed load ( $\mathrm{udl}$ ) is equal to $10 \times 10^{5} \mathrm{~N} / \mathrm{m}^{2}$ the aspect ratio of the plate is varying.

c. Variable thermal environment: The thermal response of FGM simply supported plate under variable thermal environment is performed on a square FGM plate. The temperature of top ceramic surface is varied from $50^{\circ} \mathrm{C}$ to $400^{\circ} \mathrm{C}$.

d. Variable thermal environment under constant mechanical load: The thermo-mechanical response of FGM plate for variable thermal environment under constant mechanical load is performed on a square simply supported FGM plate. The temperature of top ceramic surface is varied from $50^{\circ} \mathrm{C}$ to $400^{\circ} \mathrm{C}$. The value of the udl is set equal to $10 \times 10^{5} \mathrm{~N} / \mathrm{m}^{2}$.

\section{NUMERICAL RESULTS}

\subsection{Effect of aspect ratio $(a / b)$ in constant thermal environment}

Constant thermal environment is applied on a simply supported FGM plate and the aspect ratio is varied. The effect of various volume fractions and various laws i.e. PFGM and S-FGM are studied. The results are presented in terms of strain $\left(e_{x}\right)$ and shear strain $\left(e_{x y}\right)$.

\subsubsection{Strain $\left(\mathbf{e}_{\mathrm{x}}\right)$}

Figure 1 and Figure 2 present the variation of strain $\left(\mathrm{e}_{\mathrm{x}}\right)$ with changes in aspect ratio $(\mathrm{a} / \mathrm{b})$ considering $\mathrm{FGM}$ following Power and Sigmoid law respectively. Also the volume fraction exponent ' $\mathrm{n}$ ' is varied for P-FGM and SFGM.

The observations are as follow from the Figure 1 and Figure 2 :

- As the aspect ratio increases strain in all types of FGM reduces, it attains a minimum value when aspect ratio is kept unity, it increases again when aspect ratio is increased further beyond 1 .

- $\quad$ Strain has a steep decline between aspect ratio 0.5 and 1 . Thereafter steep rise in strain between aspect ratio 1 and 2 is observed.

- Strain for plate made of FGM are found to be lesser than the strain for plate made of metal. For example at aspect ratio unity,

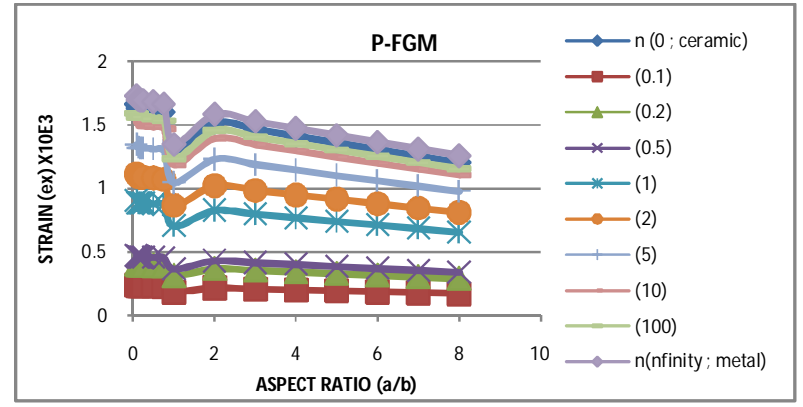

Figure 1: Strain $\left(\mathrm{e}_{\mathrm{x}}\right)$ and aspect ratio $(\mathrm{a} / \mathrm{b})$ under constant temperature (P-FGM)

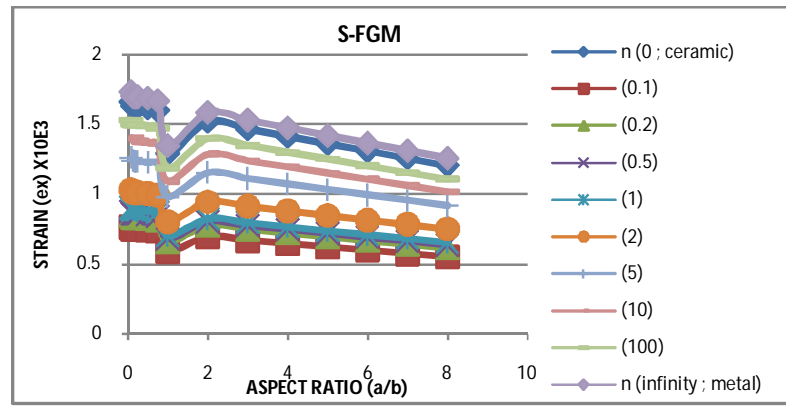

Figure 2: Strain $\left(e_{x}\right)$ and aspect ratio $(a / b)$ under constant temperature (S-FGM)

in ceramic plate $(n=0)$ the strain is approximately 0.0013 whereas in metal plate $(n=\propto)$, it is 0.00135 . The strain is more in pure ceramic and metal plate as compared to FGM plates $(0<\mathrm{n}<\propto)$.

\subsubsection{Shear Strain (exy)}

Figure 3 and Figure4 present the variation of shear strain $\left(\mathrm{e}_{\mathrm{xy}}\right)$ with changes in aspect ratio $(\mathrm{a} / \mathrm{b})$ considering $\mathrm{FGM}$ following Power and Sigmoid law respectively. Also the volume fraction exponent ' $\mathrm{n}$ ' is varied for P-FGM and SFGM.

The observations are as follow from the Figure 3 and Figure4 :

- As the aspect ratio increases shear strain in all types of FGM rises, it attains amaximum value when aspect ratio is kept unity, it diminishes when aspect ratio is increased further beyond 1 .

- At aspect ratio 1 , in ceramic plate $(n=0)$ the shear strain is approximately 0.021 whereas in metal plate $(n=\propto)$, it is 0.022 . The shear strain is more in pure ceramic and metal plate as compared to FGM plates $(0<\mathrm{n}<\propto)$.

- The shear strain is approximately 0.0089 for ceramic rich region $(\mathrm{P}-\mathrm{FGM}-\mathrm{n}=0.1)$ and it is 0.0187 for metal rich region $(\mathrm{P}-\mathrm{FGM}-\mathrm{n}=100)$. It shows that shear strain for ceramic rich region is lower than that of metal rich region. 
Manish Bhandari, International Journal of Emerging Trends in Engineering Research, 8(4), April 2020, 950 - 955

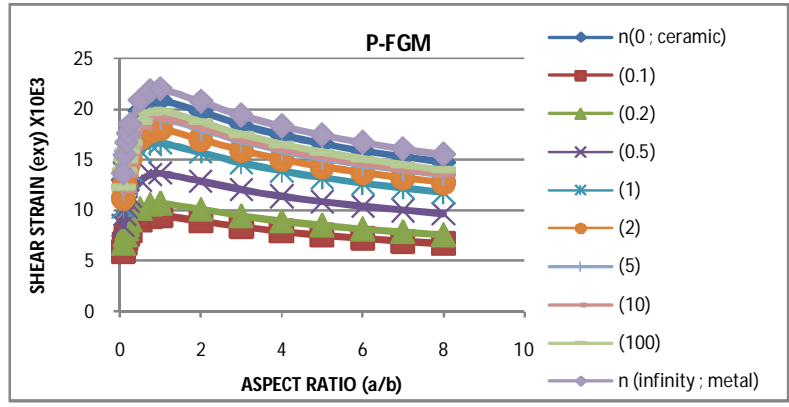

Figure 3: Shear Strain $\left(\mathrm{e}_{\mathrm{xy}}\right)$ and aspect ratio $(\mathrm{a} / \mathrm{b})$ under constant temperature (P-FGM)

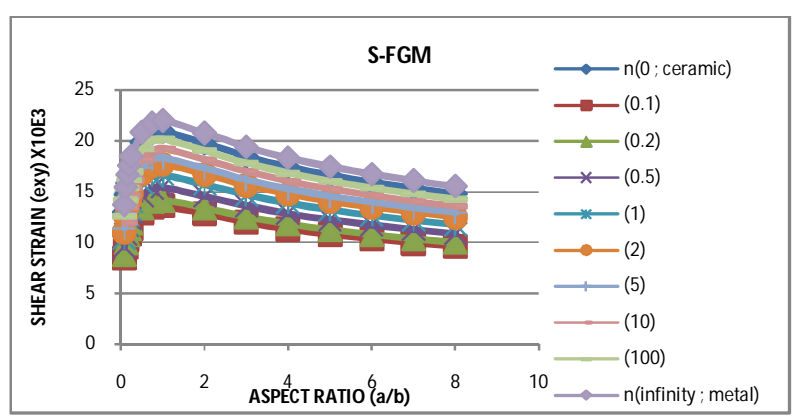

Figure 4: Shear Strain $\left(\mathrm{e}_{\mathrm{xy}}\right)$ and aspect ratio $(\mathrm{a} / \mathrm{b})$ under constant temperature $(\mathrm{S}-\mathrm{FGM})$

\subsection{Effect of aspect ratio $(\mathrm{a} / \mathrm{b})$ in constant thermal environment under mechanical load}

Constant thermal environment and mechanical udl are applied on a simply supported FGM plate and the aspect ratio is varied. The volume fraction exponent ' $n$ ' is also varied for P-FGM and S-FGM.Strain $\left(e_{x}\right)$ and shear strain $\left(\mathrm{e}_{\mathrm{xy}}\right)$ are presented.

\subsubsection{Strain (ex)}

Figure5 and Figure6present the variation of strain $\left(e_{x}\right)$ with changes in aspect ratio $(a / b)$ considering FGM following Power and Sigmoid law respectively. Also the volume fraction exponent ' $\mathrm{n}$ ' is varied for P-FGM and SFGM.

The observations are as follow from the Figure 5 and Figure 6 :

- As the aspect ratio increases the strain $\left(e_{x}\right)$ is increased rapidly and it attains maximum value at aspect ratio unity i.e. square plate

- As the aspect ratio is further increases strain reduces moderately upto aspect ratio 3 .

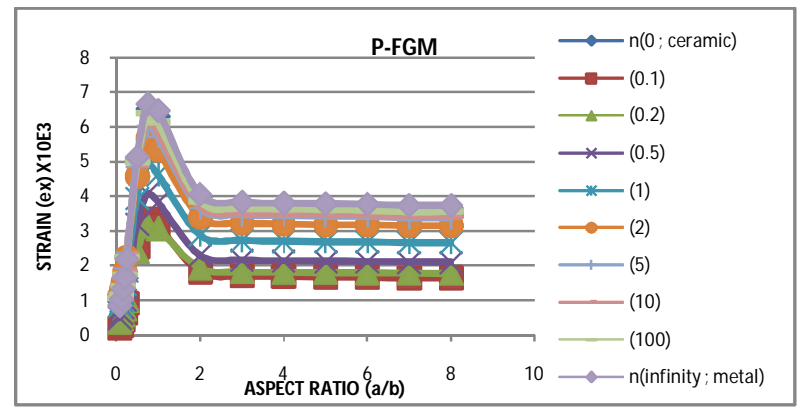

Figure 5: Strain $\left(\mathrm{e}_{\mathrm{x}}\right)$ and aspect ratio $(\mathrm{a} / \mathrm{b})$ under thermomechanical load (P-FGM)

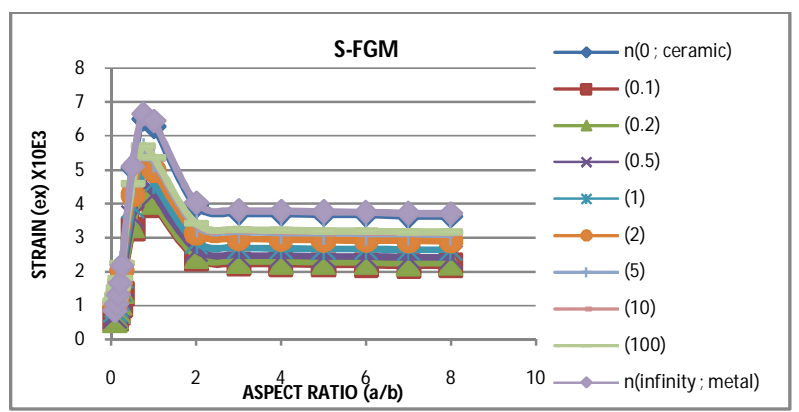

Figure 6: Strain $\left(\mathrm{e}_{\mathrm{x}}\right)$ and aspect ratio $(\mathrm{a} / \mathrm{b})$ under thermomechanical load (S-FGM)

\subsubsection{Shear Strain (exy)}

Figure 7 and Figure 8 present the variation of shear strain $\left(\mathrm{e}_{\mathrm{xy}}\right)$ with changes in aspect ratio $(\mathrm{a} / \mathrm{b})$ considering FGM following Power and Sigmoid law respectively. Also the volume fraction exponent ' $\mathrm{n}$ ' is varied for P-FGM and SFGM.

The observations are as follow from the Figure 7 and Figure8 :

- As the aspect ratio increases upto 2 shear strain increases for bothall values of ' $\mathrm{n}$ ' in P-FGM and S-FGM.

- After aspect ratio 2, shear strain remains almost constant.

- Shear Strain for plate made of FGM are found to be lesser than the strain for plate made of metal. For example at aspect ratio unity, in ceramic plate $(n=0)$ the shear strain is approximately 0.0280 whereas in metal plate $(n=\propto)$, it is 0.0282 . The strain is more in pure ceramic and metal plate as compared to FGM plates $(0<\mathrm{n}<\propto)$.

- At aspect ratio 3 shear strain is approximately 0.0192 for ceramic rich region $(\mathrm{P}-\mathrm{FGM}-\mathrm{n}=0.1)$ and it is 0.034 for metal rich region $(\mathrm{P}-\mathrm{FGM}-\mathrm{n}=100)$. It shows that shear strain for ceramic rich region is lower than that of metal rich region. 


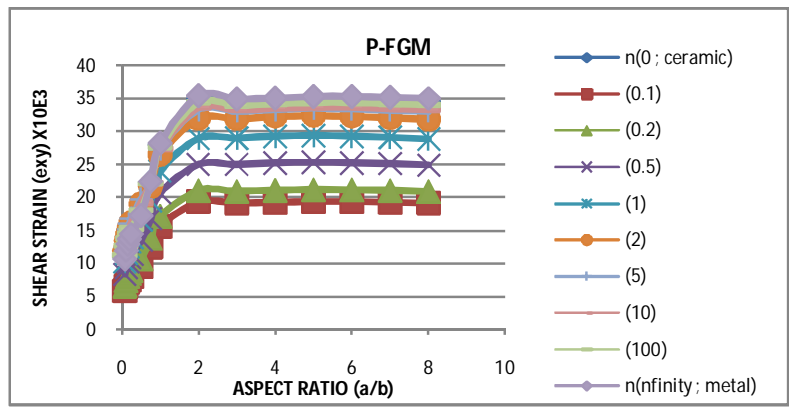

Figure 7: Shear strain $\left(\mathrm{e}_{\mathrm{xy}}\right)$ and aspect ratio $(\mathrm{a} / \mathrm{b})$ under thermomechanical load (P-FGM)

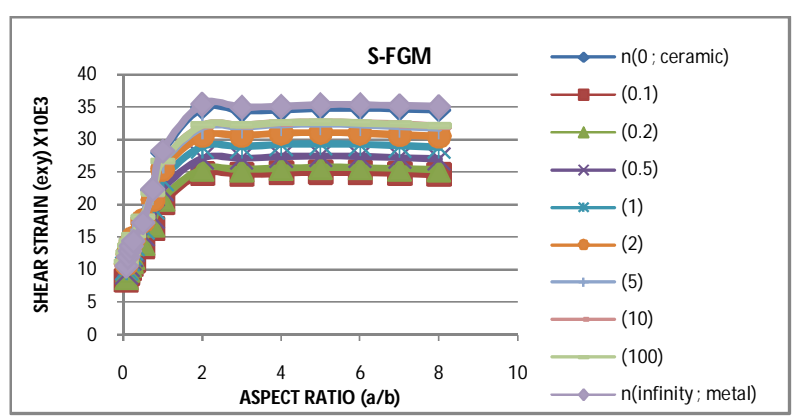

Figure 8: Shear strain $\left(\mathrm{e}_{\mathrm{xy}}\right)$ and aspect ratio $(\mathrm{a} / \mathrm{b})$ under thermomechanical load (S-FGM)

\subsection{Variable thermal environment}

A simply supported square $(a / b=1)$ FGM platesubject to varying thermal environment is considered and results are reported and discussed. The thermal analysis is performed by varying temperature of ceramic surface from $50^{\circ} \mathrm{C}$ to $400^{\circ} \mathrm{C}$. The P-FGM and S-FGM with various values of volume fraction exponents ' $\mathrm{n}$ ' are studied. Strain $\left(\mathrm{e}_{\mathrm{x}}\right)$ and shear strain $\left(\mathrm{e}_{\mathrm{xy}}\right)$ are presented.

\subsubsection{Strain $\left(e_{x}\right)$}

The numerical results for variation of strain $\left(e_{x}\right)$ with change in temperature are depicted in Figure 9 and Figure 10 for PFGM and S-FGM respectively.

The following observations are made by comparing the strain $\left(\mathrm{e}_{\mathrm{x}}\right)$ for various values of temperature and types of FGM:

- As the value of volume fraction exponent ' $n$ ' is increased i.e. approaching towards metal region, the magnitude of strain is increased. For example in case of P-FGM at $400^{\circ} \mathrm{C}$ when $\mathrm{n}$ is equal to 0.5 the strain is about 0.0015 , however when volume fraction exponent ' $\mathrm{n}$ ' is increased to 10 , the strain is increased to 0.005 .

- It is also found that at the lower temperature, for the various volume fraction exponents, the magnitude of strain is almost same; however as the temperature is increased, the value of strain for the various volume fraction exponent is also found to increase linearly.

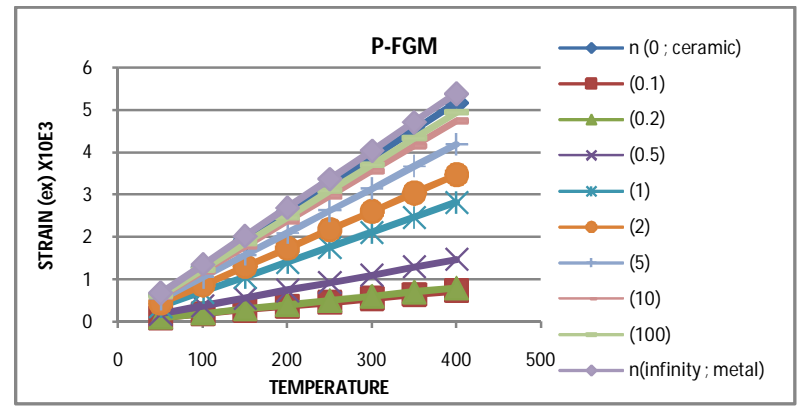

Figure 9: Strain $\left(\mathrm{e}_{\mathrm{x}}\right)$ and thermal environment (P-FGM)

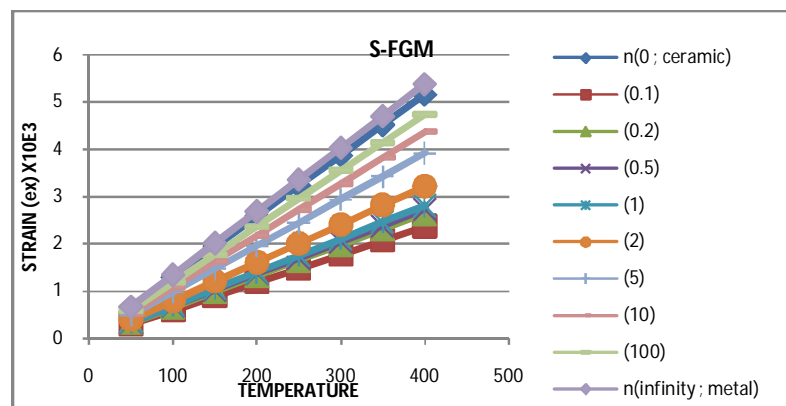

Figure 10: Strain $\left(e_{x}\right)$ and thermal environment (S-FGM)

\subsubsection{Shear Strain $\left(e_{x y}\right)$}

The numerical results for variation of shear strain $\left(\mathrm{e}_{\mathrm{xy}}\right)$ with change in temperature are depicted in Figure 11 and Figure 12 for P-FGM and S-FGM respectively.

It can be observed from the Figure 11 and Figure 12 that

- As the value of volume fraction exponent ' $n$ ' is increased i.e. approaching towards pure metal, the magnitude of shear strain is increased. For example in case of P-FGM at $400^{\circ} \mathrm{C}$ when $\mathrm{n}$ is equal to 0.5 the shear strain is about 0.055 , however when volume fraction exponent ' $n$ ' is increased to 10 , the shear strain is increased to 0.075 .

- It is also found that at the lower temperature for the various values of volume fraction exponent, the magnitude of shear strain is almost same; however as the temperature increases, the shear strain curves for the various values of volume fraction exponent are diverged.

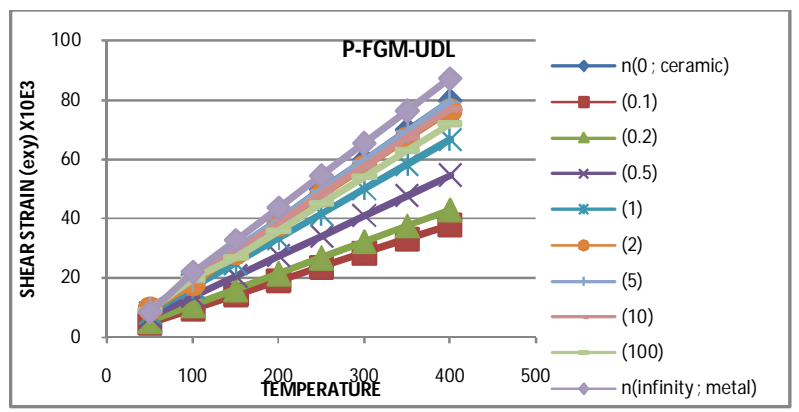

Figure 11: Shear strain $\left(\mathrm{e}_{\mathrm{xy}}\right)$ and thermal environment (P-FGM) 


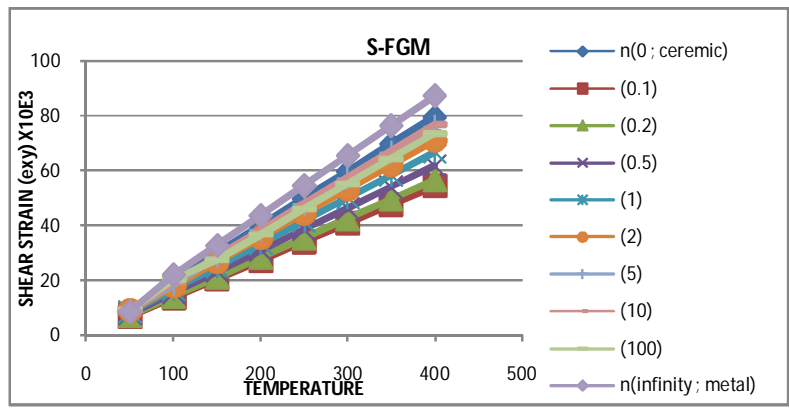

Figure 12: Shear strain $\left(\mathrm{e}_{\mathrm{xy}}\right)$ and thermal environment $(\mathrm{S}-\mathrm{FGM})$

\subsection{Variable thermal environment with constant mechanical load}

A simply supported square $(\mathrm{a} / \mathrm{b}=1)$ FGM plate subject to constant uniformly distributed load $\left(1 \times 10^{6} \mathrm{~N} / \mathrm{m}^{2}\right)$ with varying thermal environment is considered. Thermomechanical analysis is performed by varying temperature of ceramic surface from $50^{\circ} \mathrm{C}$ to $400^{\circ} \mathrm{C}$, while that of metallic surface, the temperature is kept $0^{\circ} \mathrm{C}$.

The P-FGM and S-FGM with various values of volume fraction exponents ' $n$ ' are studied. Strain $\left(e_{x}\right)$ and shear strain $\left(\mathrm{e}_{\mathrm{xy}}\right)$ are presented.

\subsubsection{Strain $\left(\mathbf{e}_{\mathrm{x}}\right)$}

The numerical results for variation of strain (ex) with change in temperature are depicted in Figure 13 and Figure 14 for P-FGM and S-FGM respectively.

The observations which are drawn from Figure 13 and Figure 14 are:

- As the value of volume fraction exponent ' $n$ ' is increased i.e. approaching towards pure metal, the magnitude of strain is increased. For example in case of P-FGM at $400^{\circ} \mathrm{C}$ when $\mathrm{n}$ is equal to 0.5 the non-dimensional strain is about 0.003 , however when volume fraction exponent ' $n$ ' is increased to 10 , the strain is increased to 0.0048 .

- It is observed that the strain in pure ceramic and pure metal plate continuously decreases as the temperature is increased, however in the FGM plates the rate of decrement of strain reduces as the temperature is increased. Further, when the temperature is increased beyond $350{ }^{\circ} \mathrm{C}$, the strain curves of FGM plates intersect those of pure metal and ceramic plates.

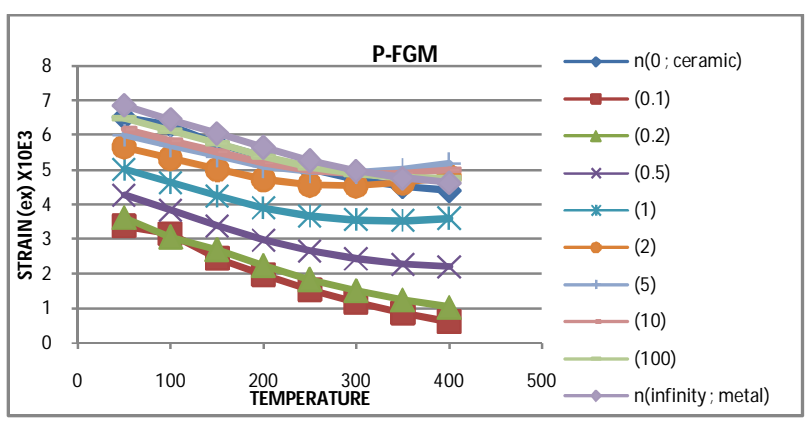

Figure 13: Strain $\left(e_{x}\right)$ and thermal environment under mechanical load (P-FGM)

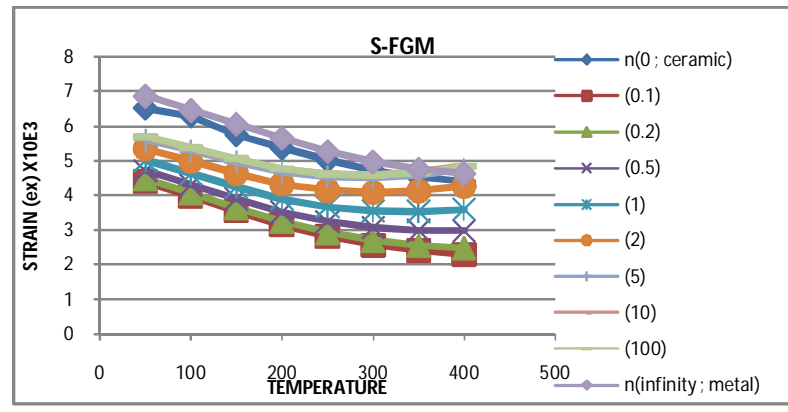

Figure 14: Strain $\left(\mathrm{e}_{\mathrm{x}}\right)$ and thermal environment under mechanical load (S-FGM)

\subsubsection{Shear Strain (exy)}

The numerical results for variation of shear strain $\left(e_{x y}\right)$ with change in temperature are depicted in Figure 15 and Figure 16 for P-FGM and S-FGM respectively.

The observations which are drawn from Figure 15 and Figure 16 are:

- It is found that at the lower temperature for the various values of volume fraction exponent, the magnitude of shear strain is almost same; however as the temperature increases, the shear strain curves for the various values of volume fraction exponent gets diverged.

- It is also interesting to note that at higher temperatures the FGM with high value of volume fraction exponent ' $n$ ' (' $n$ ' more than 5) the shear strain is more than metal plate.

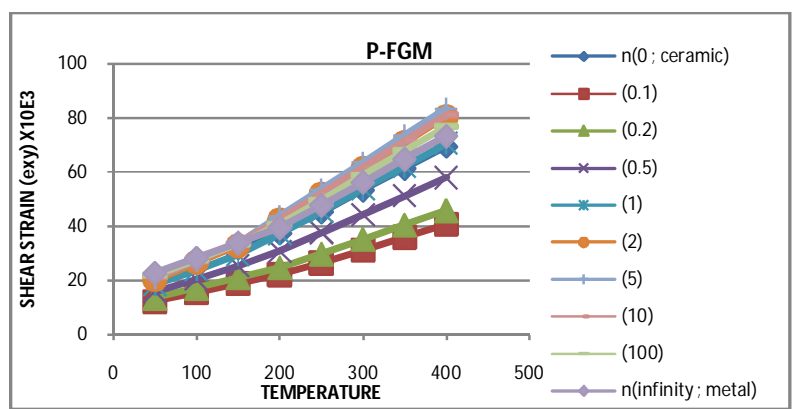

Figure 15: Shear strain $\left(\mathrm{e}_{\mathrm{xy}}\right)$ andthermal environment under mechanical load (P-FGM)

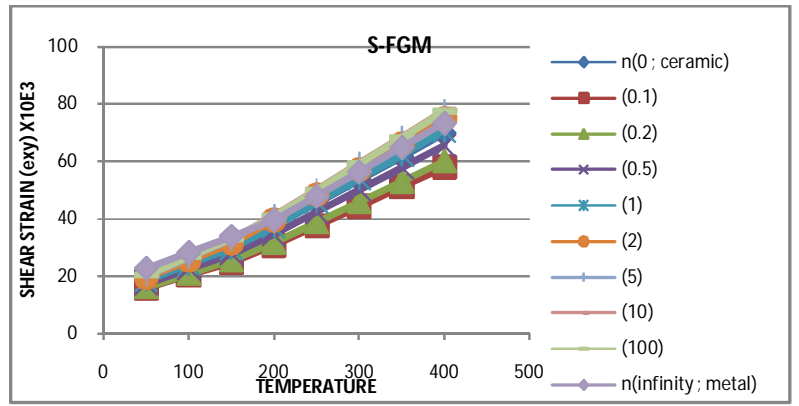

Figure 16: Shear strain $\left(\mathrm{e}_{\mathrm{xy}}\right)$ and thermal environment under mechanical load (S-FGM)

\section{CONCLUSION}

In the present work FGM plates have been subjected to thermal and thermomechanical load. Parametric studies have been recorded for various values of volume fraction 
Manish Bhandari, International Journal of Emerging Trends in Engineering Research, 8(4), April 2020, 950 - 955

exponents and Power and Sigmoid law of distribution. Following conclusions may be drawn:

A. The ceramic has a lower coefficient of thermal expansion than metal. The ceramic has greater value of modulus of elasticity as compared to the metal. That is the reason the FGM plates do not exhibit intermediate response for strain and shear strain to pure metal and pure ceramic plate.

B. Strain values computed for FGM plate are less than isotropic plate (e.g. fully ceramic or fully metal plate) for lower temperatures. As we increase the temperature, the deflection for the various volume fraction exponents diverge. P-FGM $(n=0.5)$ plate has the smallest strain among all kinds of FG plate.

C. FG plates have got a higher capaability to bear thermal stresses and hence they sustains at elevated temperatures.

\section{REFERENCES}

1. Butcher RJ, Rousseau CE and Tippur HV., "A Functionally Graded Particulate and Composite: Preparation, Measurements and Failure Analysis", Acta Metallrgica Inc, Vol. 47, PP.259-268, 1999. https://doi.org/10.1016/S1359-6454(98)00305-X

2. Reddy JN, Zhen-QC., "Three-Dimensional Thermo mechanical Deformations of Functionally Graded Rectangular Plates”, Eur. J Mech. A/Solids, Vol. 20, PP. 841-855, 2001.

https://doi.org/10.1016/S0997-7538(01)01174-3

3. Dai KY, Liu GR, Han X, Lim KM., "Thermo mechanical Analysis of Functionally Graded Material Plates Using Element-Free Galerkin Method", Computers and Structures, Vol. 83, PP. 487-1502, 2005.

https://doi.org/10.1016/j.compstruc.2004.09.020

4. Yasser MS, Naotake N., "Numerical Evaluation of The Thermo mechanical Effective Properties of a Functionally Graded Material Using the Homogenization Method", Int $\mathbf{J}$ of Solids and Structures, Vol. 45, PP. 3494-3506, 2008. https://doi.org/10.1016/j.ijsolstr.2008.02.012

5. Kyung-Su N, Ji-Hwan K., "Comprehensive Studies on Mechanical Stress Analysis of Functionally Graded Plates", World Academy Of Science, Engg. And Technology, Vol. 60, PP. 768-773, 2011.

6. Momennia S, Akbarzadeh AH. "Analysis of Functionally Graded Rectangular and Circular Plates Using Finite Element Method",16th Int Conference on Composite Structures Iccs 16; 2011.

7. Vanam BCL, Rajyalakshmi M, Inala R., "Static Analysis of an Isotropic Rectangular Plate Using Finite Element Analysis (Fea)", J of Mechanical Engg. Research, Vol. 4, PP. 148-162, 2012. https://doi.org/10.5897/JMER11.088

8. Nguyen-Xuan H, Locv T, Chienh T, Nguyen-Thoi T., "Analysis of Functionally Graded Plates by an Efficient Finite Element Method with Node-Based Strain Smoothing", Thin-Walled Structures, Vol. 54, PP. 1-18., 2012. https://doi.org/10.1016/j.tws.2012.01.013

9. Bhandari M. and Purohit K.,"Response of Functionally Graded Material Plate under Thermomechanical Load Subjected to Various Boundary Conditions", International Journal of Metals. 2015 . http://dx.doi.org/10.1155/2015/416824.

10. Sharma K. and Kumar D., "Elastoplastic Stability and Failure Analysis of FGM Plate with Temperature Dependent Material Properties under Thermomechanical Loading", Latin American Journal of Solids and Structures, Vol. 14, PP.13611386, 2017. https://doi.org/10.1590/1679-78253747

11. Eko J., Adi S. and Marwan E., "Characteristics of Temperature changes and Stress of Float Glassunder Heat Radiation”, IJETER, Vol. 7:9, PP. 228-233. 